\title{
Squeezing the $\left[\mathrm{Cu}-\mathrm{OH} \cdots \mathrm{H}_{2} \mathrm{O}-\mathrm{Cu}\right]^{3+}$ bridge by cryptate encapsulation
}

Andrew D. Bond, Sofia Derossi, Frank Jensen, Frank B. Larsen, Christine J.

McKenzie, Jane Nelson*

University of Southern Denmark, Department of Chemistry, Campusvej 55, 5230 Odense M, Denmark. Biomedical Sciences, University of Ulster, Coleraine, BT52 1 SA, N Ireland.

Materials:

Methanol and ethanol used in ligand synthesis were of technical grade supplied by Bie and Bernsten A/S. Acetonitrile used was Scharlau DNA synthesis grade, labelled water content $<0.001 \%$.

\section{Syntheses:}

Cryptand $\mathrm{L}^{1}$ was prepared as described previously (ref. 4) using the $2+3$ Schiff base condensation of tren with $p$-benzene dialdehyde, followed by borohydride reduction. Purity was confirmed by ${ }^{1} \mathrm{H},{ }^{13} \mathrm{C}$ NMR, MS, and by comparison of the infrared spectrum with authentic samples.

\section{$\left[\mathrm{Cu}_{2} \mathrm{~L}^{1}\right]\left(\mathrm{ClO}_{4}\right)_{4} \cdot 4 \mathrm{H}_{2} \mathrm{O}(1)$}

$2 \mathrm{mmol}$ of $\mathrm{L}^{1}$ dissolved in $4 \mathrm{ml} \mathrm{MeOH}$ was added dropwise to $2.2 \mathrm{mmol} \mathrm{Cu}\left(\mathrm{ClO}_{4}\right)_{2} .6 \mathrm{H}_{2} \mathrm{O}$ in $5 \mathrm{ml} \mathrm{MeOH}$. An immediate heavy blue-green precipitate was observed, which was filtered off in $92 \%$ yield after $2 \mathrm{hrs}$.

Elemental analysis: C, 39.34; H, 5.08; N, $10.07 \%$.

Calculated $\left(\mathrm{C}_{36} \mathrm{H}_{54} \mathrm{~N}_{8} \mathrm{Cl}_{4} \mathrm{Cu}_{2} \mathrm{O}_{16} \cdot 4 \mathrm{H}_{2} \mathrm{O}\right) \mathrm{C}, 38.5 ; \mathrm{H}, 4.85 ; \mathrm{N}, 10.0 \%$.

\section{$\left[\mathrm{Cu}_{2} \mathbf{L}^{1}\left(\mathrm{H}_{2} \mathrm{O}\right)(\mathrm{OH})\right]\left(\mathrm{ClO}_{4}\right)_{3}(2)$}

$50 \mathrm{mg}$ of $\mathbf{1}$ was dissolved in $10 \mathrm{ml} \mathrm{MeCN}$, filtered to remove any trace of undissolved solid, covered with punctured parafilm and allowed to evaporate slowly in air for $4 / 5$ days. During this time, a mid-green polycrystalline solid formed on the sides of the flask with yield ca. $28 \%$. Powder diffraction was performed on this bulk solid. Single crystals were obtained by diethylether diffusion into an acetonitrile solution of the solid. 
According to Lu et al. (ref. 15), the above procedure should produce the cyanide-bridged complex $\left[\mathrm{Cu}_{2} \mathrm{~L}^{1} \mathrm{CN}\right]\left(\mathrm{ClO}_{4}\right)_{3} \cdot 2 \mathrm{H}_{2} \mathrm{O}$ (3). We were unable to repeat this. The source of acetonitrile in ref. 15 was not mentioned although it was described as Analar grade, used as supplied. On direct enquiry, we were informed by Prof. Lu that the solvent was Tianjin A.R. $\operatorname{Re}(a) g e n t$ grade, distilled before use.

In order to elucidate the discrepancy between our product from acetonitrile and that of Lu et al., data from 2 and an authentic sample of cyanide bridged complex $\mathbf{3}$ was compared. We prepared 3 by the deliberate procedure of reacting equimolar amounts of $\mathrm{KCN}$ with complex 1. The complex 3 formed readily in $>70 \%$ yield and characteristic weak but sharp infrared absorption $\left(2181 \mathrm{~cm}^{-1}\right)$ confirmed cyanide incorporation. In our hands, complex $\mathbf{3}$ is highly favoured over formation of complex 2 if cyanide is present in the acetonitrile solution. Single crystals of 3 gave identical lattice parameters to those reported for $\left[\mathrm{Cu}_{2} \mathrm{~L}^{1} \mathrm{CN}\right]\left(\mathrm{ClO}_{4}\right)_{3} \cdot 2 \mathrm{H}_{2} \mathrm{O}$; complete data collection was not undertaken. A full description of our work with the cyanide complexes of a series of dicopper(II)cryptates will appear in due course (Ref 16).

Single-crystal X-ray diffraction:

Single-crystal X-ray diffraction on a crystal of 2 was performed at 180(2) K on a BrukerNonius X8APEX-II CCD diffractometer. Thin-slice diffraction images were integrated using SAINT v. 7.06a (Bruker AXS, 2003) and a multi-scan absorption correction was applied using SADABS v. 2.10 (Sheldrick, 2003). The structure was solved and refined using SHELXTL v.6.10 (Sheldrick, 2000). One perchlorate moiety was modelled as disordered over two orientations around a 3-fold axis. A second perchlorate moiety is disordered about a site of $-31 \mathrm{~m}$ symmetry. A single $\mathrm{O}$ atom was included with $2 / 3$ occupancy, summing to $4 \mathrm{O}$ atoms in total. CCDC deposition number 250369.

\section{Powder X-ray diffraction:}

5-10 $\mathrm{mg}$ of 2 was ground with $1 \mathrm{ml} \mathrm{MeOH}$ in a mortar. The resulting slurry was dripped onto the centre of a glass plate and the solvent was allowed to evaporate to leave a thin coating. Data were collected at room temperature (295 K) on a Siemens D5000 instrument (CuKa radiation) over the $2 \theta$ range $5-70^{\circ}$ using $0.02^{\circ}$ steps, $25 \mathrm{~s}$ per step. Peak picking and latticeparameter refinement were performed using WinXPow v.1.06 (Stoe \& Cie, 1999). 
The X-ray powder diffraction profile of the bulk sample of 2 (Fig. S1) confirms that it constitutes mainly $\mathbf{2}$, by comparison to a simulation from the single crystal structure. Lattice parameters refined from the PXRD data give $a=b=9.928(4), c=25.863(8) \AA, V=2208(2)$ $\AA^{3}$, the moderate expansion compared to the low-temperature single-crystal structure arising since the PXRD data were collected under ambient conditions (295 K). Additional peaks principally in the region $c a .11 \leq 2 \theta \leq 13^{\circ}$, indicate the presence of some minor second phase. A reasonable assignment for a second product is a bicarbonate-bridged complex $\left[\mathrm{Cu}_{2} \mathrm{~L}^{1}\left(\mathrm{HCO}_{3}{ }^{-}\right)\right]^{3+}$, similar to that which crystallizes from the dicopper(II) cryptate of the isomeric $m$-xylyl ligand (Ref. 16). To date, single crystals of this phase suitable for X-ray diffraction analysis have not been forthcoming and we have not therefore confirmed its identity conclusively. It is certain, however, that the PXRD profile for the bulk sample of 2 exhibits no correlation with that generated from the reported crystal structure of $3{ }^{15}$ Thus, at least in our hands, there is no formation of 3by acetonitrile $\mathrm{C}-\mathrm{C}$ cleavage cascade reaction.

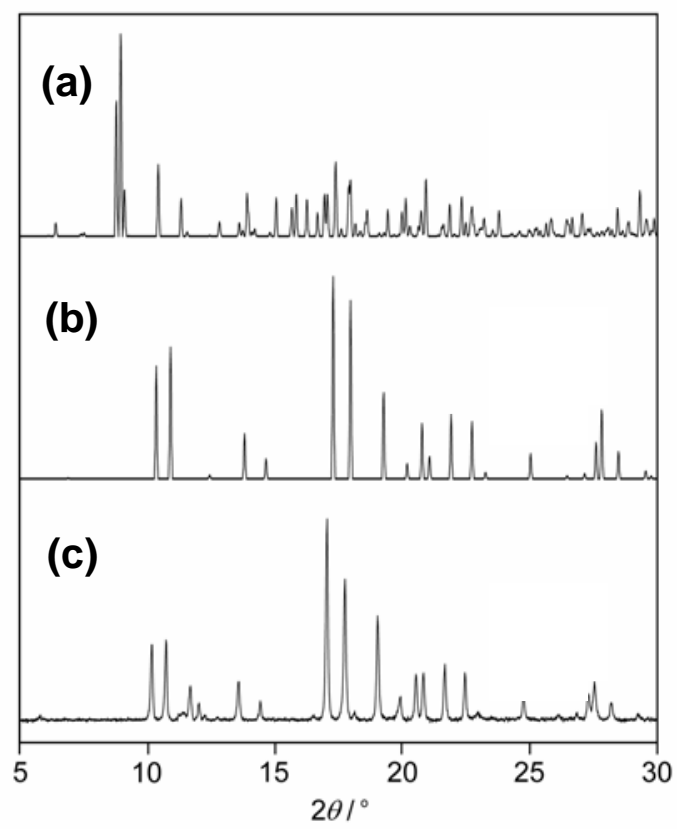

Figure S1. X-ray powder diffraction profiles. (a) Simulation from the published structure of 3. (b) Simulation from the single-crystal structure of 2 . (c) Measured from the bulk sample of 2. 
Refined lattice parameters for 1 from PXRD data (295 K):

Trigonal, space group $P-31 c$

$a=b=9.928(4) \AA$

$c=25.863(8) \AA$

Vol $=2208(2) \AA^{3}$

\begin{tabular}{rrlllllrrrr}
\hline & $h$ & $k$ & $l$ & $d($ obs $)$ & $d($ calc $)$ & $2 \theta($ obs $)$ & $2 \theta($ calc $)$ & $\Delta(2 \theta)$ & $I($ obs $)$ & $I($ calc $)$ \\
\hline 1 & 1 & 0 & 0 & 8.5978 & 8.5978 & 10.280 & 10.280 & 0.0001 & 39.2 & 55.6 \\
2 & 1 & 0 & 1 & 8.1566 & 8.1588 & 10.838 & 10.835 & 0.0030 & 41.0 & 64.9 \\
3 & 0 & 0 & 4 & 6.4680 & 6.4658 & 13.680 & 13.684 & -0.0046 & 20.0 & 22.2 \\
4 & 1 & 0 & 3 & 6.0882 & 6.0878 & 14.537 & 14.538 & -0.0009 & 9.1 & 9.9 \\
5 & 1 & 0 & 4 & 5.1672 & 5.1676 & 17.147 & 17.145 & 0.0016 & 100.0 & 100.0 \\
6 & 1 & 1 & 0 & 4.9641 & 4.9640 & 17.854 & 17.854 & -0.0006 & 72.3 & 87.9 \\
7 & 1 & 1 & 2 & 4.6339 & 4.6343 & 19.138 & 19.136 & 0.0016 & 53.3 & 43.3 \\
& 1 & 1 & -2 & & 4.6343 & & 19.136 & 0.0016 & & 0.2 \\
8 & 1 & 0 & 5 & 4.4316 & 4.4323 & 20.020 & 20.017 & 0.0034 & 11.3 & 7.5 \\
9 & 2 & 0 & 0 & 4.2999 & 4.2989 & 20.640 & 20.644 & -0.0046 & 23.4 & 26.6 \\
10 & 2 & 0 & 1 & 4.2409 & 4.2407 & 20.930 & 20.931 & -0.0010 & 23.7 & 11.2 \\
11 & 2 & 0 & 2 & 4.0791 & 4.0794 & 21.770 & 21.769 & 0.0019 & 27.2 & 31.4 \\
12 & 1 & 1 & 4 & 3.9373 & 3.9374 & 22.565 & 22.564 & 0.0010 & 23.1 & 6.1 \\
& 1 & 1 & -4 & & 3.9374 & & 22.564 & 0.0010 & & 21.9 \\
13 & 2 & 0 & 4 & 3.5789 & 3.5799 & 24.859 & 24.851 & 0.0071 & 11.8 & 12.3 \\
14 & 2 & 0 & 5 & 3.3068 & 3.3062 & 26.941 & 26.946 & -0.0053 & 3.3 & 2.5 \\
15 & 1 & 1 & 6 & 3.2525 & 3.2547 & 27.399 & 27.381 & 0.0185 & 13.4 & 2.6 \\
& 1 & 1 & -6 & & 3.2547 & & 27.381 & 0.0185 & & 7.2 \\
16 & 2 & 1 & 1 & 3.2250 & 3.2243 & 27.638 & 27.644 & -0.0057 & 18.9 & 0.5 \\
& 2 & 1 & -1 & & 3.2243 & & 27.644 & -0.0057 & & 26.7 \\
17 & 2 & 1 & 2 & 3.1507 & 3.1517 & 28.303 & 28.294 & 0.0088 & 8.3 & 2.9 \\
& 2 & 1 & -2 & & 3.1517 & & 28.294 & 0.0088 & & 10.5 \\
18 & 2 & 1 & 3 & 3.0410 & 3.0408 & 29.346 & 29.348 & -0.0016 & 2.9 & 0.0 \\
& 2 & 1 & -3 & & 3.0408 & & 29.348 & -0.0016 & & 3.7 \\
\hline & & & & & & & & & &
\end{tabular}

Figure of merit, $\mathrm{F}(18)=150.9(0.004,30)$

[de Wolff, P. M. J. Appl. Cryst. 1968, 2, 89] 